\title{
Un análisis de la gestión por competencias en la empresa española De la teoría a la práctica
}

\section{Cuauhtémoc Guerrero}

Dávalos

Universidad Michoacana de San Nicolás de Hidalgo gdavalos@zeus.umich.mx

\section{Mireia Valverde}

Aparicio

Universidad Rovira y Virgili mireia.valverde@urv.net

María Tatiana Gorjup Universidad Rovira y Virgili mariatatiana.gorjup@urv.cat

\section{Resumen}

Este trabajo aborda el tema de la gestión por competencias, una técnica para la gestión de los recursos humanos orientada a mejorar el rendimiento de los empleados y de la organización. Asimismo, se plantean interrogantes sobre el alto grado de implementación de esta técnica y su relación con el rendimiento empresarial en empresas de sectores específicos y con resultados económicos diversos.

Palabras clave: competencias, recursos humanos, rendimiento empresarial, empresa, cualificación. 


\title{
An analysis of the management competency in Spanish companies. From theory to practice
}

\begin{abstract}
This paper is about the competency management, a technique for human resources management aimed at improving the performance of employees and organization performance. Specifically, there are concerns about the high degree of implementation of this technique and its relationship with management performance in specific industries with various economic outcomes.
\end{abstract}

Keywords: competences, human resources, management performance, company, cualification.

\section{Introducción}

La gestión por competencias es una técnica de recursos humanos que tiene sus antecedentes en los estudios del comportamiento humano en el campo de la psicología, en donde destacan los trabajos de McClelland (1973), Boyatzis (1982), Spencer y Spencer (1993), quienes fundaron una consultora de recursos humanos llamada Hay/McBer en los Estados Unidos, hoy Hay Group. En esos estudios se apunta a las características innatas o subyacentes de la persona en combinación con otros aspectos tales como los conocimientos y la motivación hacia el mejor desempeño en las diversas actividades profesionales. Otras aportaciones de la gestión por competencias han sido a través de los trabajos de los autores franceses Le Boterf (2001), Levy-Leboyer (1997) y Mandon (1990), quienes destacan una perspectiva diferente a la planteada por McClelland y sus seguidores, proponiendo una visión de competencias que va más allá de ser un concepto genérico y centrado en el potencial del individuo. Para estos autores franceses la acepción de competencia es, asimismo, indisociable del desarrollo de las personas, que puede originarse por la formación y la experiencia; en una palabra, la visión francesa de competencias es constructivista. En este mismo escenario se destacan los trabajos de algunos autores británicos (Horton, 2000a; Woodruffe, 1991, 1993 y 2000; Lysaght y Altschuld, 2000; McLagan, 1997; Mirabile, 1997), que hacen referencia a la capacidad de las personas en un contexto específico de estándares profesionales donde la competencia, además de que se puede observar y evaluar, también se puede entrenar y desarrollar. Precisamente es Inglaterra donde el modelo de 
certificación de competencias cobra más fuerza en la década de 1980 a través de la creación de la National Council for Vocational Qualifications (Consejo Nacional de Cualificación Profesional) siendo un país pionero en el modelo de certificar las competencias laborales en el nivel mundial.

Por otra parte, en la revisión de la literatura técnica se observó que en los últimos años la acepción y práctica de esta técnica fue un factor distintivo y estratégico del que muchas empresas se valen para conseguir más ventajas que sus competidores a través de las capacidades individuales enfocadas al puesto de trabajo. Debido a ello, la gestión por competencias es un tema insoslayable en la función de los recursos humanos (Dolan et al. 2003) que influye no sólo en el ámbito de las decisiones empresariales de las organizaciones, sino en otros campos como la educación ${ }^{1}$ y la administración pública, inspirando en cierto modo medidas en materia de empleo y de formación ${ }^{2}$.

\section{Listados de competencias desde la visión de tres corrientes}

La diversidad de despliegues de comportamientos que se observan de los individuos en las áreas laborales y el origen de los mismos es causa de que en la teoría de competencias existan distintas descripciones de competencias que, en buena medida, origina que se construyan listas de competencias. Asimismo, "los marcos de competencias se pueden establecer para una organización seleccionando las competencias correctas y expresándolas en el lenguaje correcto" (Moloney, 2001, p. 42). Ahora bien, la justificación de expresar listados desde tres enfoques obedece a las distintas visiones de cada uno de ellos.

\footnotetext{
${ }^{1}$ En Europa en el ámbito universitario se produce un movimiento centrado en las competencias: "la declaración de Bolonia" de junio de 1999, donde el objetivo es la creación de un espacio europeo de enseñanza superior coherente, compatible y competitivo que sea atractivo para los estudiantes europeos y los estudiantes y académicos de otros continentes (Cámara de Comercio Barcelona, 2010).

${ }^{2}$ Concretamente, la CEDEFOP (2010) calcula que en 2020 el 31.5\% de todos los puestos de trabajo exigirán cualificaciones de nivel terciario o superior, y que cerca del $34 \%$ de la mano de obra dispondrá de ellas. Aproximadamente el $50 \%$ de los puestos de trabajo requerirá cualificaciones de nivel medio, y cerca del $48 \%$ de la mano de obra estará cualificada a ese nivel. Cerca del 18\% de la mano de obra no estará cualificada o tendrá un nivel bajo de cualificación, mientras que el $18.5 \%$ de los puestos de trabajo no requerirá cualificación o sólo será necesaria una cualificación baja. Vistas estas tendencias, aunque la correspondencia no es perfecta, parece ser que Europa no va tan desencaminada. A pesar de que los niveles de cualificaciones previstos estén alineados en términos generales es probable que en 2020 el mercado laboral europeo registre un excedente de algunas competencias a la par que una escasez en el caso de otras. Es posible que la gente disponga de cualificaciones académicas, mientras que lo que deseen los empresarios sean cualificaciones profesionales.
} 
Concretamente, los autores americanos favorecen los procesos subyacentes y las competencias, lo que indica que son características generales en las que se ignora el contexto en el que se aplican. Para los autores que se identifican con el enfoque francés, en cambio, las competencias tienen una connotación integral y relacional, es decir, se toma en cuenta el contexto en el que se aplican las competencias. Por último, la corriente a la que hemos denominado británica, tiene la peculiaridad de ser eminentemente conductista porque no toma en cuenta la conexión de las tareas que realiza un individuo en los procesos de evaluación y, por tanto, no favorece su desarrollo o su transformación en el ámbito profesional (véase el cuadro 1).

\section{Cuadro 1}

\section{Listas de competencias}

\begin{tabular}{|c|c|c|c|}
\hline $\begin{array}{l}\text { Corrientes de } \\
\text { competencias }\end{array}$ & $\begin{array}{l}\text { Corriente americana } \\
\text { de competencias }\end{array}$ & Corriente francesa & Corriente británica \\
\hline $\begin{array}{l}\text { Autores } \\
\text { representativos }\end{array}$ & $\begin{array}{l}\text { Boyatzis, 1982; } \\
\text { McClelland, 1973; } \\
\text { Spencer y Spencer, } \\
\text { 1993; Alles, 2006; } \\
\text { Goleman, 2003; 2004 }\end{array}$ & $\begin{array}{l}\text { Le Boterf 1991; } \\
\text { 1998; 2001; Levy- } \\
\text { Leboyer,1997; Pérez } \\
1997\end{array}$ & $\begin{array}{l}\text { Horton, 2000; Tolley, 1987; } \\
\text { Hoffmann, 1999; Virtanen, } \\
\text { 2000; Kamoche 1997; y } \\
\text { Holmes, 1995; Woodruffe, } \\
1993\end{array}$ \\
\hline $\begin{array}{l}\text { Listados de } \\
\text { competencias }\end{array}$ & $\begin{array}{l}\text { Listas de } \\
\text { competencias de tipo } \\
\text { genérico o universal. } \\
\text { En principio su } \\
\text { lista comprende } 20 \\
\text { competencias que } \\
\text { son comunes en } \\
\text { cualquier ámbito en el } \\
\text { que los individuos se } \\
\text { desempeñen. }\end{array}$ & $\begin{array}{l}\text { La elaboración de las } \\
\text { listas de competencias se } \\
\text { lleva a cabo atendiendo } \\
\text { una visión holística; es } \\
\text { decir, ajustadas a sus } \\
\text { necesidades y de acuerdo } \\
\text { al entorno en el que se } \\
\text { encuentran. }\end{array}$ & $\begin{array}{l}\text { Hay un criterio que las } \\
\text { competencias se expresan } \\
\text { con base a estándares } \\
\text { de actuación. Su visión } \\
\text { está centrada en que las } \\
\text { competencias deben ser } \\
\text { evaluadas por un organismo } \\
\text { certificador reconocido. } \\
\text { En este caso suele ser el } \\
\text { gobierno el principal órgano } \\
\text { gue lo lleva a cabo. }\end{array}$ \\
\hline
\end{tabular}

\section{Líneas de investigación en la gestión por competencias}

En este apartado se muestran algunas líneas de investigación que se han desarrollado en la gestión por competencias; la presentación de las investigaciones se hizo atendiendo a características comunes tales como colectivo de estudio y sectores analizados. En este sentido, la clasificación por sectores comprende al sector empresarial y el sector público, por lo que el primer grupo del sector empresarial corresponde a trabajos que se han realizado sobre identificación, evaluación y certificación de competencias gerenciales y de empleados, así como en la elaboración de diccionarios de competencias en países como Estados Unidos, Inglaterra, Es- 
paña, Suecia, México y Brasil. Concretamente estos estudios estuvieron a cargo de investigadores como Boyatzis (1982), Spencer y Spencer (1993), Sandberg (2000), Jordan y Cartwright (1998), Brotherton y Watson (2001), Birdir y Pearson (2000), Brophy y Kiely (2002), Hart et al. (1999), Hansson (2001), Cowling et al. (1999), Mertens y Wilde (2003), Balcells (1993), Benício de Mello et al. (2007), Pascoal et al. (2008), Del Pilar et al. (2008), Malasia et al. (2008) y Kavitha et al. (2010). En el sector público es en el Reino Unido donde existe el mayor número de aportaciones en este campo; algunos de esos trabajos muestran diversos resultados de la evaluación y certificación de las competencias en las organizaciones públicas de dicho país. Se destacan los trabajos de autores como Fielding (1988), Horton (2000a , 2000b), Burchell y Westmoreland (1999) y Rosenfeld (1999).

Existen pocas evidencias empíricas de que la gestión por competencias incrementa los resultados de las empresas; sin embargo, existe un marco jurídico en el que se contempla que los tres sectores básicos de la sociedad, tales como la administración pública, las empresas y universidades deben colaborar en la construcción de un catálogo nacional de cualificaciones y competencias en el territorio español, el cual pueda contribuir a facilitar el desarrollo y la movilidad de los trabajadores, una vez que los aprendizajes formales e informales hayan sido acreditados, según lo establece el Real Decreto 13/1995, y la Ley Orgánica 5/2002, de 19 de junio, de las Cualificaciones y de la Formación Profesional del Ministerio de la Presidencia (BOE, 2002), incluso se apunta la posibilidad de que exista un gap entre la retórica empresarial que propone a la gestión por competencias como una técnica a implementar extensivamente ${ }^{3}$.

Sin embargo, la realidad, donde la falta de datos puede estar encubriendo diferentes grados de la implementación y utilización efectiva de esta técnica; es decir, el sistema a través de las competencias pretende ser coherente con el mercado interno de la empresa porque los títulos académicos y las consiguientes pruebas no son

\footnotetext{
${ }^{3}$ En este sentido Rodríguez (1999) afirma que a partir de la década de 1980 las competencias se vuelven un tema obligado para los investigadores y consultores de recursos humanos, incluso, las iniciativas emprendidas por organismos mundiales en el ámbito de la educación y el trabajo, como las de la OCDE, han marcado ejes rectores en la implementación de modelos educativos basados en competencias, así como en organismos que certifican las competencias de los empleados arguyendo diversas ventajas de la formación profesional. Ésa es la razón por la que en países como México y España, entre otros, hay un marco jurídico que obliga a implementar modelos basados en competencias, los cuales tienen su origen en acuerdos internacionales sobre políticas económicas que acaban repercutiendo en ámbitos laborales y educativos.
} 
suficientes para explicar aquello de lo que es capaz de hacer una persona para que su trabajo sea sobresaliente; por ello, la CEOE (2002:43) afirma que su "objetivo inmediato es mejorar los resultados de la empresa presentando modelos concretos de competencias profesionales exitosas, adaptadas a un contexto de trabajo específico, para que se mejore el desempeño". El no hacerlo, desde la perspectiva de Haddad (1997):

[...] va a resultar más difícil pronosticar tanto la clase de competencias que se van a necesitar en el futuro como su duración. Los factores mencionados exigen de una mayor movilidad de la mano de obra, que ha de ser flexible para adquirir nuevas competencias. (p.34)

En cambio, sabemos que actualmente el $80 \%$ de los organismos públicos en el Reino Unido realizan gestión por competencias en las áreas de recursos humanos (Horton, 2000a). Otros países que conforman la Unión Europea, como Francia, de acuerdo con Peretti (1997) cuentan con un balance de competencias en un intento de las autoridades de este país por orientar la carrera profesional de los trabajadores, el cual puede operar a petición de la empresa o a petición de los empleados en el marco de un plan de formación. ${ }^{4}$

Pero, a pesar de la gran importancia que se le atribuye a la gestión por competencias, tanto en la literatura como en la legislación vigente de España desafortunadamente casi no existen evidencias empíricas (más allá de estudios de casos) que describan el grado de implantación con mayor profundidad de esta técnica de gestión en las empresas (públicas y privadas) españolas.

Por todo ello es claro que en el territorio español es necesario profundizar en la realización de nuevos estudios en los que se evidencie tanto el alcance como el verdadero potencial de este sistema. Nuestro trabajo tiene la finalidad de analizar la implementación de la gestión por competencias en sectores concretos del territorio español. Las preguntas que se plantean como un marco de investigación son:

${ }^{4}$ En Francia la organización MEDEF (Movimiento de Empleadores en Francia) desde hace algunos años inició un proyecto para identificar una lista de criterios comunes y prácticas sobre gestión por competencias para informar y sensibilizar a las empresas en distintos países de Europa para tratar de asesorarlas y darles seguimiento, intercambiando experiencias que faciliten la transferencia y capitalización de las buenas prácticas en los recursos humanos en la utilización (CEOE, 2002). 
¿Qué grado de implantación tiene la gestión por competencias en la empresa española?

Para dar respuesta a esta pregunta en primer lugar se revisará la literatura para, posteriormente, analizar en profundidad los diversos aspectos sobre la implantación de la gestión por competencias aplicados a la empresa española. En concreto se analizarán: 1) las técnicas que se utilizan para identificar competencias; 2) el grado de dificultad que experimentan las empresas en el proceso de implantación de sus sistemas de gestión por competencias; y 3 ) los agentes que intervienen en la implantación de los sistemas de gestión por competencias de los sectores investigados.

¿El rendimiento de las empresas en qué medida afecta a la implantación del modelo de gestión por competencias?

La respuesta a esta pregunta comprende el análisis de la implantación del sistema de gestión por competencias en dos sectores concretos correspondientes a los sectores españoles financiero y textil, los cuales poseen características organizativas divergentes relacionados especialmente con los actores, técnicas y procedimientos que intervienen en la gestión de sus recursos humanos.

En los siguientes apartados se desarrollará en primer lugar el marco teórico de la gestión por competencias en cuanto al tipo de metodologías que se utilizan para identificar y evaluar las competencias de los empleados; además, se muestra en qué políticas de recursos humanos se utiliza este tipo de gestión. En la última parte de este trabajo se explica el tipo de metodología utilizada, así como los resultados y conclusiones que se desprenden del mismo.

\section{Metodologías empleadas para evaluar e identificar las competencias en la ges- tión de los recursos humanos}

Somos conscientes de que, en principio, el estudio de la gestión por competencias plantea una problemática conceptual dado que competencia o competencias son acepciones polisémicas y, como bien afirma Prieto (1997), se acomodan a la audiencia y el medio en el que se ponen en práctica en un momento determinado; por ello, proponemos que las competencias son recursos aptitudinales y actitudinales que las personas ponen en juego al convivir con otras personas y al realizar actividades laborales y profesionales de manera destacada. 
Ahora bien, en la aplicación de políticas de recursos humanos existen técnicas que pueden ser herramientas útiles para medir el nivel de competencias que poseen los individuos. De esta forma, algunas de ellas atendiendo a sus ventajas e inconvenientes se clasifican en técnicas cuantitativas y cualitativas (Flanagan, 1954; Spencer; McClelland y Spencer, 1994; Salgado y Moscoso, 2001; Porret, 2008; Pereda y Berrocal, 2005; Alles, 2006) (véase los cuadros 2 y 3 ).

\section{Cuadro 2}

\section{Técnicas cuantitativas}

\begin{tabular}{l|l|l|l}
\hline \multicolumn{1}{c|}{ Metodología } & \multicolumn{1}{|c|}{ Procedimiento } & Ventajas que implica & \multicolumn{1}{c}{ Desventajas } \\
\hline $\begin{array}{l}\text { Experimentación } \\
\text { (Duverger, 1996) }\end{array}$ & $\begin{array}{l}\text { Actividades específicas con } \\
\text { grupos artificiales. }\end{array}$ & $\begin{array}{l}\text { Efectivo en pruebas de } \\
\text { grupo. }\end{array}$ & $\begin{array}{l}\text { Relacionado con } \\
\text { los costos y poca } \\
\text { practicidad en las } \\
\text { empresas. }\end{array}$ \\
\hline $\begin{array}{l}\text { Encuestas } \\
\text { (Mirabile, 1997) }\end{array}$ & $\begin{array}{l}\text { Rellenado de un formato } \\
\text { por los implicados. }\end{array}$ & $\begin{array}{l}\text { Ampliamente aplicado } \\
\text { a los puestos de trabajo. } \\
\text { Los datos fácilmente } \\
\text { pueden ser comparados. }\end{array}$ & $\begin{array}{l}\text { Dificultad en } \\
\text { determinados niveles } \\
\text { culturales. Posible } \\
\text { extensión en el tiempo } \\
\text { de corrección. }\end{array}$ \\
\hline $\begin{array}{l}\text { Factorial } \\
\text { (Duverger, 1996) }\end{array}$ & $\begin{array}{l}\text { Establece correlaciones } \\
\text { entre las variables. }\end{array}$ & $\begin{array}{l}\text { Efectivo en el estudio } \\
\text { de aptitudes que trata la } \\
\text { psicología social. }\end{array}$ & $\begin{array}{l}\text { Poco preciso en el } \\
\text { estudio de las actitudes. }\end{array}$ \\
\hline
\end{tabular}

Con base en la información que se muestra en el cuadro 2 algunas de estas técnicas pueden utilizarse para identificar y evaluar competencias individuales; particularmente, algunas organizaciones utilizan los cuestionarios para que los encuestados describan con claridad y precisión qué se debe saber y saber-hacer en un puesto de trabajo.

En el caso de la experimentación, su relación con la identificación con las competencias se puede ver por ejemplo en lo concerniente con las pruebas de grupo para designar líder, en las que se pretende apreciar las aptitudes de liderazgo. Por su parte, el análisis factorial es utilizado ampliamente utilizado en el terreno de la psicología social en el estudio de las aptitudes, el cual es objeto de numerosas experiencias. 


\section{Cuadro 3}

\section{Técnicas cualitativas}

\begin{tabular}{|c|c|c|c|c|c|}
\hline Métodos & $\begin{array}{l}\text { Mayor } \\
\text { utilidad }\end{array}$ & $\begin{array}{l}\text { Procedi- } \\
\text { miento }\end{array}$ & $\begin{array}{l}\text { Aplicación } \\
\text { en recursos } \\
\text { humanos }\end{array}$ & $\begin{array}{l}\text { Mayores } \\
\text { ventajas }\end{array}$ & Mayores desventajas \\
\hline $\begin{array}{l}\text { Observación, } \\
\text { discusión de } \\
\text { grupos, diarios, } \\
\text { etc. }\end{array}$ & $\begin{array}{l}\text { Análisis de las } \\
\text { conductas en } \\
\text { el puesto de } \\
\text { trabajo. }\end{array}$ & $\begin{array}{l}\text { Registro de las } \\
\text { observaciones. }\end{array}$ & $\begin{array}{l}\text { Seguridad y } \\
\text { salud como } \\
\text { parte de otros } \\
\text { métodos. }\end{array}$ & $\begin{array}{l}\text { Se puede obtener } \\
\text { razonablemente } \\
\text { la secuencia } \\
\text { de los trabajos } \\
\text { manuales. }\end{array}$ & $\begin{array}{l}\text { No es muy efectivo para } \\
\text { identificar características } \\
\text { subyacentes (Boam y } \\
\text { Sparrow, 1992; Anguera, } \\
\text { 1985). }\end{array}$ \\
\hline $\begin{array}{l}\text { Centros de } \\
\text { evaluación } \\
\text { (assessment } \\
\text { centers). } \\
\text { Pruebas } \\
\text { situacionales } \\
\end{array}$ & $\begin{array}{l}\text { Evaluación de } \\
\text { los implicados } \\
\text { en el puesto de } \\
\text { trabajo. }\end{array}$ & $\begin{array}{l}\text { Analiza el } \\
\text { conjunto de } \\
\text { tareas del } \\
\text { puesto y las } \\
\text { competencias. }\end{array}$ & $\begin{array}{l}\text { Selección, } \\
\text { evaluación de } \\
\text { empleados. }\end{array}$ & $\begin{array}{l}\text { Varios sujetos y } \\
\text { competencias se } \\
\text { evalúan a la vez. }\end{array}$ & $\begin{array}{l}\text { Presenta elevado costo. Se } \\
\text { preparan diversas pruebas. } \\
\text { Resistencia cultural (De } \\
\text { Ansorena, 1999; Espinoza, } \\
\text { 1994; Joiner, 2002; Acosta, } \\
\text { 1997). }\end{array}$ \\
\hline $\begin{array}{l}\text { Entrevistas: } \\
\text { competencias y } \\
\text { profundidad }\end{array}$ & $\begin{array}{l}\text { Análisis de } \\
\text { los aspirantes } \\
\text { a ocupar el } \\
\text { puesto. }\end{array}$ & $\begin{array}{l}\text { Registro de los } \\
\text { datos. }\end{array}$ & $\begin{array}{l}\text { Identificación } \\
\text { de } \\
\text { competencias y } \\
\text { selección. }\end{array}$ & $\begin{array}{l}\text { Proporciona } \\
\text { información } \\
\text { profunda. }\end{array}$ & $\begin{array}{l}\text { El tiempo de procesamiento } \\
\text { se puede alargar. } \\
\text { Incrementando el costo } \\
\text { (Salgado y Moscoso, 2001; } \\
\text { Olaz, 1998) }\end{array}$ \\
\hline $\begin{array}{l}\text { Datos } \\
\text { biográficos } \\
\text { y escucha } \\
\text { biográfica }\end{array}$ & $\begin{array}{l}\text { Análisis de } \\
\text { curriculum. }\end{array}$ & $\begin{array}{l}\text { Examina } \\
\text { situaciones } \\
\text { pasadas. }\end{array}$ & $\begin{array}{l}\text { Reclutamiento } \\
\text { y Selección. }\end{array}$ & $\begin{array}{l}\text { Es la carta de } \\
\text { presentación. } \\
\text { En la escucha } \\
\text { biográfica se } \\
\text { contrastan } \\
\text { situaciones del } \\
\text { pasado. }\end{array}$ & $\begin{array}{l}\text { Con respecto a los datos } \\
\text { biográficos puede ser } \\
\text { discriminatorio (Melián, } \\
\text { 1995; Leboterf, 2001). }\end{array}$ \\
\hline $\begin{array}{l}\text { Repertorio de } \\
\text { Grid }\end{array}$ & $\begin{array}{l}\text { Define listas } \\
\text { de conceptos } \\
\text { personales. }\end{array}$ & $\begin{array}{l}\text { Se crea una lista } \\
\text { comparando } \\
\text { triangular- } \\
\text { mente cada } \\
\text { elemento }\end{array}$ & $\begin{array}{l}\text { Requerimiento } \\
\text { de necesidades } \\
\text { en las áreas de } \\
\text { trabajo. }\end{array}$ & $\begin{array}{l}\text { Flexible y fácil } \\
\text { de usar. Además } \\
\text { de su bajo } \\
\text { costos. }\end{array}$ & $\begin{array}{l}\text { Existe riesgo de no tener } \\
\text { credibilidad entre los } \\
\text { empleados (Kelly, 1955; } \\
\text { Levy-Leboyer, 1997; } \\
\text { Parry,1996). }\end{array}$ \\
\hline $\begin{array}{l}\text { Fenomeno- } \\
\text { lógico }\end{array}$ & $\begin{array}{l}\text { Áreas } \\
\text { educativas. }\end{array}$ & $\begin{array}{l}\text { Observación, } \\
\text { descripción sin } \\
\text { análisis. }\end{array}$ & $\begin{array}{l}\text { Prácticamente } \\
\text { no existe en las } \\
\text { organizaciones. }\end{array}$ & $\begin{array}{l}\text { Puede ser } \\
\text { un método } \\
\text { innovador en } \\
\text { áreas educativas. }\end{array}$ & $\begin{array}{l}\text { Difícil de implantar. Es poco } \\
\text { difundido (Sandberg, 1995). }\end{array}$ \\
\hline Delphi & $\begin{array}{l}\text { Detección de } \\
\text { necesidades de } \\
\text { formación. }\end{array}$ & $\begin{array}{l}\text { Los expertos } \\
\text { intercambian en } \\
\text { rondas sucesivas } \\
\text { estimaciones. }\end{array}$ & $\begin{array}{l}\text { Entrenamiento } \\
\text { y capacitación. }\end{array}$ & $\begin{array}{l}\text { Es una } \\
\text { alternativa de } \\
\text { pronóstico para } \\
\text { toma decisiones. }\end{array}$ & $\begin{array}{l}\text { Puede ser muy subjetivo, } \\
\text { además complicado para } \\
\text { reunir los expertos (Richards } \\
\text { y Curran, 2002; Pereda y } \\
\text { Berrocal, 2005; Mitchell, } \\
\text { 1991). }\end{array}$ \\
\hline $\begin{array}{l}360 \text { grados y } \\
\text { autoevaluación. }\end{array}$ & $\begin{array}{l}\text { Evaluación del } \\
\text { desempeño. }\end{array}$ & $\begin{array}{l}\text { Registro de } \\
\text { opiniones de } \\
\text { empleados u } \\
\text { otros. }\end{array}$ & $\begin{array}{l}\text { Evaluación y } \\
\text { desarrollo de } \\
\text { carrera. }\end{array}$ & $\begin{array}{l}\text { Detección de } \\
\text { necesidades para } \\
\text { elaborar planes. }\end{array}$ & $\begin{array}{l}\text { Varía de acuerdo con el } \\
\text { contexto laboral. Requiere } \\
\text { funcionar con más técnicas } \\
\text { (Levy-Leboyer, 2000; Maurer } \\
\text { et al., 2002;Atkins y Wood, } \\
\text { 2002; Bohene, 2002; Totten y } \\
\text { Orlikoff, 2002). }\end{array}$ \\
\hline $\begin{array}{l}\text { Incidentes } \\
\text { críticos }\end{array}$ & $\begin{array}{l}\text { Funcionamiento } \\
\text { en el puesto. }\end{array}$ & $\begin{array}{l}\text { Registro y } \\
\text { evaluación de } \\
\text { los incidentes. }\end{array}$ & $\begin{array}{l}\text { Evaluación del } \\
\text { desempeño. }\end{array}$ & $\begin{array}{l}\text { Captura } \\
\text { comportamientos } \\
\text { no rutinarios. }\end{array}$ & $\begin{array}{l}\text { La colección de datos es } \\
\text { larga; su traducción es } \\
\text { difícil. Se eleva el costo } \\
\text { considerablemente (Spencer } \\
\text { y Spencer, 1993; Boam y } \\
\text { Sparrow, 1992). }\end{array}$ \\
\hline $\begin{array}{l}\text { Entrevista de } \\
\text { incidentes } \\
\text { críticos }(\mathrm{BEI})\end{array}$ & $\begin{array}{l}\text { Análisis del } \\
\text { potencial de los } \\
\text { implicados. }\end{array}$ & $\begin{array}{l}\text { Registro de } \\
\text { hechos del } \\
\text { pasado. }\end{array}$ & $\begin{array}{l}\text { Selección, } \\
\text { desarrollo de } \\
\text { carrera. }\end{array}$ & $\begin{array}{l}\text { Libre de } \\
\text { prejuicios de } \\
\text { género y cultura. }\end{array}$ & $\begin{array}{l}\text { El costo puede incrementarse. } \\
\text { Se requiere experiencia de } \\
\text { los entrevistadores (Boyatzis, } \\
\text { 1982; Spencer y Spencer, } \\
\text { 1993). }\end{array}$ \\
\hline
\end{tabular}


La información del cuadro 3 muestra un resumen de técnicas que se pueden utilizar para identificar y evaluar las competencias de los empleados atendiendo al objeto que persiguen cada una de ellas, tipo de procedimientos para aplicarlas, en qué procesos de recursos humanos se utilizan y cuáles son las ventajas e inconvenientes para implementarlas.

\section{Políticas de RHH basadas en el modelo de gestión por competencias}

La justificación de gestionar los recursos humanos por competencias, desde el punto de vista de Pereda y Berrocal (1999), es porque le permite a la dirección de recursos humanos centrarse en las características de las personas que requiere a corto, medio y largo plazos para poder hacer frente a los cambios como consecuencia de la evolución de los negocios. Esto es, los procesos de selección para muchas organizaciones van más allá de tomar en cuenta un currículo; ahora, los individuos que se pretende contratar necesariamente deben presentar comportamientos que son tomados en cuenta en tareas relevantes dentro de la organización por los evaluadores de selección de recursos humanos; por lo tanto, en este apartado se exponen diversas acciones que se implementan en los procesos de recursos humanos en el ámbito de las competencias.

\section{Planificación de recursos humanos}

Carneiro et al. (2003) consideran que la empresa deberá tomar en consideración una serie de aspectos previos que pueden influir para bien o para mal en el proceso de implementación de la gestión por competencias. Según Pereda y Berrocal (1999, p. 114) "el proceso de planificación de los recursos humanos es un proceso sistemático de elaboración, dentro del marco de la estrategia de la organización, que permitirá disponer de las personas necesarias, con las competencias adecuadas"; por su parte, Hellriegel et al. (2005) aseguran que la forma de conocer las competencias de los empleados es a través de un inventario de competencias o archivo detallado por cada empleado.

\section{Reclutamiento}

En palabras de Merlane (1994, p. 47): "el reclutamiento es una acción decisiva en la actualidad, en lo que supone como voluntad de anticipación de necesidades de cualificaciones y de identificación de competencias estratégicas por adquirir". Para Ahmad y Schroeder (2002) la importancia de este proceso podrá contribuir 
positivamente, si se pone el debido cuidado en las competencias de los empleados. Sin embargo, Wood y Payne (1999) afirman que este proceso es complejo de implementarse debido a la diversidad de competencias que pueden mostrar los candidatos y a la dificultad de evaluarlas.

\section{Selección}

Puchol (2007) y Davenport (2000) señalan que la importancia de las competencias corresponde al gran interés que en los últimos años han mostrado las empresas más avanzadas en los contratos psicológicos. Para Whiddett y Hollyforde (2007) se valora mejor la competencia de los individuos cuando puede ser observada durante el inicio de tareas relevantes en ambientes empresariales reales. De ahí que Alles (2006) sostenga que los comportamientos permiten llegar a la determinación de las competencias y a su nivel o grado. Concretamente, para Fernández (2005) el perfil de competencias del puesto marca los requerimientos por exigir en un candidato que pretende incorporarse a la empresa. Finalmente, Spencer, McClelland y Spencer (1994), por su parte, revelan la existencia de mejoras en el desempeño laboral que van desde el 19\% al 78\% como resultado de utilizar los métodos de selección con base en competencias; además, han mostrado importantes disminuciones en la rotación de los empleados (hasta en un 90\%).

\section{Formación y entrenamiento}

Para Le Boterf (2001) y Alamillo y Villamor (2002) las empresas pasan a centrarse en las necesidades individuales de los empleados, conectando esas necesidades con un tipo de formación que contribuya más a desarrollar las competencias detectadas. En este sentido, Gómez-LLera y Pin (1994) consideran que los directivos deben crear y desarrollar las capacidades y habilidades necesarias para el desarrollo integral de la persona y para el buen funcionamiento de la organización. Cornford y Aghanasou (1995) consideran que aun cuando se reconozca que la gestión por competencias es un factor de éxito importante en los programas de formación y entrenamiento debe ser, además, el medio para conseguir que los empleados logren desarrollar un nivel de expertos.

\section{Evaluación del desempeño}

Para autores como Cubeiro y Fernández (1998, p. 50) "las organizaciones no pueden permitirse el lujo de prescindir de la gestión por competencias. Según los 
resultados de puestos comerciales o complejos aumentan [...] entre un 30 y 72 por ciento si se utilizan programas de desarrollo y gestión del desempeño basados en competencias"; es decir, la efectividad en el desempeño se incrementa al utilizar la gestión por competencias. Levy-Leboyer (1997, p. 66) considera que "toda evaluación de competencias supone un objetivo empresarial cuando se trata de detectar los potenciales y de hacer balance de los recursos humanos de la empresa". El modelo que sugiere HayGroup (2005) es un modelo mixto que se centra en las competencias donde las organizaciones orientadas al futuro están intentando compensar sus sistemas de remuneración por desempeño con un sistema de remuneración por competencias. En definitiva, el marco de competencias dentro del sistema de evaluación que tenga implantado la empresa podrá permitir identificar de manera más equilibrada el desempeño de los trabajadores (Boam y Sparrow, 1992).

\section{Promociones}

La planificación de la sucesión es un sistema permanente para seleccionar a los empleados más competentes, que se encuentren en condiciones de movilizarse o ser transferidos a otros puestos importantes de la organización, una vez que éstos hayan quedado vacantes (Spencer y Spencer, 1993; Blanco, 2007). Para Craig (1992), la planificación de la sucesión con base en competencias puede definir qué competencias se requieren en cada uno de los niveles de la organización.

\section{Desarrollo de carrera profesional}

Los planes de carrera con base en competencias, de acuerdo con HayGroup (1996):

[...] son un método de desarrollo de futuras aptitudes, que se basa en la colocación de la persona en puestos de trabajo cuidadosamente estudiados, para proporcionarle la oportunidad de desarrollar las competencias necesarias para puestos más altos. (p. 54)

Es necesario tomar en cuenta los marcos competenciales como concepto potencial de evolución, que se convierten en el eje de las acciones que debe llevar a cabo la organización (Peretti, 1997). Las competencias proveen los marcos para el entrenamiento y el desarrollo de los empleados cuando estos combinan las técnicas, los comportamientos y la competencia en conjunto (Whiddett y Hollyforde, 2007). 


\section{Sistemas de compensación}

Consiste en retribuir a los empleados con base en el nivel de competencias que llevan a cabo en los roles de trabajo (Armstrong, 2010). No obstante, Whiddett y Hollyforde (2007) señalan que dificulta la nivelación de sueldos, ya que el mismo puesto de trabajo requiere diferentes niveles de cada competencia. Cira y Benjamín (1998) citados por Armstrong (1999) afirman que una

[...] compensación basada en competencias no es apropiada para cada organización, incluso en una organización que ya está utilizando las competencias para gestionar la actuación de sus recursos humanos o su desarrollo. Es difícil y a menudo un sistema disociador para llevar a cabo, y sólo una compañía que ya está comprometida para cambios significantes debe implantarlo (p. 304).

En el mismo sentido, Brown (1998), también citado por Armstrong (1999, p. 305), señala que "la competencia relacionada al pago, es particularmente apropiada en organizaciones donde es reconocido que las habilidades y conductas de los empleados son la clave para el éxito competitivo (...)". Para LLopart (1997) existe dificultad para inferir las probabilidades para determinar tanto el valor del beneficio que dará una competencia, como el momento en el que generará resultados económicos. En última instancia, Mertens (1997), Caveda (1997) y Spencer y Spencer (1993) opinan que la gestión por competencias para las empresas implica un costo elevado de gestión, que no siempre se encuentra en condiciones de solventar. La relación costo-beneficio en principio está solamente ligada a la gestión del personal dentro de la empresa.

\section{Resultados de la gestión por competencias}

Autores como Wright y McMahan (1992), Pfeffer (1994), Lado y Wilson (1994), Claver et al. (1996) y De Saá y García (2001) reconocen que la implicación de las competencias en los diversos procesos de recursos humanos, a través del esfuerzo individual, ayudarán a que la empresa incremente su productividad mediante la mejora del rendimiento y un aumento de la rentabilidad. Grant (1995) considera la importancia de los activos intangibles como ventaja competitiva. Wright y Snell (1991) nos ofrecen un panorama de la gestión por competencias y otros aspectos conductuales en el que las competencias, los conocimientos y las habilidades son los principales inputs de la organización. Lado y Wilson (1994) opinan que al ex- 
tender la filosofía de las competencias, en el que la innovación y la buena relación empresarial, ayudarán a generar aprendizaje organizativo y a promocionar una cultura organizacional. Arthur (1994), Huselid (1995), MacDuffie (1995) y Green (2000) ponen en evidencia que los comportamientos de los empleados produce resultados financieros positivos. En último lugar, Ulrich $(1997,2000)$ asume que la actitud positiva de los trabajadores en favor de la empresa, junto con la identificación de sus competencias y conocimientos, tendrá necesariamente repercusiones para fortalecer su compromiso de pertenencia en la organización.

De acuerdo con lo anterior, podemos resumir que la gestión por competencias es una técnica de recursos humanos que propone un conocimiento más detallado sobre las causas del desempeño de los empleados en cualquiera de los procesos de recursos humanos y su correlación con diversos resultados organizativos. Todo ello utilizando instrumentos de evaluación e identificación de competencias.

En el siguiente apartado se presenta la segunda parte de este trabajo que consiste en la metodología empleada, así como los resultados alcanzados y las conclusiones del mismo.

\section{Análisis empírico: metodología}

Más adelante se detalla el método elegido para el desarrollo de este trabajo básicamente en el diseño del instrumento de recolección de datos, tipo de sectores investigados y el modelo analítico utilizado para responder las preguntas planteadas.

\section{Características de la muestra y del proceso de recolección de la información}

La unidad de análisis para este estudio es la organización. Debido a que para el alcance y dimensión de los trabajos relacionados con este documento sería impracticable intentar obtener una muestra representativa de todas las empresas españolas, se optó por limitar la población estudiada atendiendo a dos criterios: sector y tamaño de las organizaciones.

En cuanto a la selección de sectores, se han identificado dos sectores económicos radicalmente distintos con base en sus resultados generales en el territorio español: sector textil y sector financiero; este último, de acuerdo con la literatura (De Saá y García, 2001), es un sector que no sólo obtiene buenos resultados, sino que ha re- 
volucionado en la gestión de sus recursos humanos en las últimas décadas; esto es, el sector ha estado inmerso en el proceso de liberalización y competencia, lo que le da una vital importancia a su personal como factor clave de su éxito empresarial. Todo lo contrario ocurre en el sector textil, la crisis financiera paulatinamente ha comenzado a hacer estragos en las economías de este sector (Tremosa y Trigo, 2003); además del inminente riesgo de la desaparición de muchas empresas por la difícil situación, han afrontado procesos de liberación y globalización que han resultado en una gran competencia por parte de otros países, especialmente China. Aunado a lo anterior, la peculiar crisis que envuelve actualmente al sector textil, así como su magnitud, ha provocado que el manejo del listado de estas empresas sea complejo, no así para las instituciones financieras.

Para determinar la muestra de los sectores de nuestro estudio se realizó lo siguiente: en primer lugar, se generó el listado de empresas a partir de bases de datos oficiales; en segundo lugar, se contactó a las empresas de cada uno de los listados tomando el criterio de seleccionar en forma aleatoria 1 de cada 2 empresas del listado; y, en tercer lugar, se envió el cuestionario. A continuación, se presentan las características de las muestras resultantes para cada uno de los sectores analizados:

- Para el caso del sector textil, se empleó la base de datos SABI (2004) formada por un total de 10000 empresas distribuidas en todo el territorio español. Para efectos de que las muestras de los dos sectores fueran comparables, se optó por incluir en el listado de empresas textiles sólo aquellas que contaban con 40 o más empleados. En este sentido se identificaron 929 empresas de las cuales se contactaron 464 empresas. Finalmente, han respondido el cuestionario un total de 133 empresas con una tasa de respuesta del 28.66\%; sin embargo, la muestra final desechó cuatro cuestionarios por falta de datos; por consiguiente, sólo se utilizó la información de 129 cuestionarios restantes en las empresas textiles.

- La muestra de empresas pertenecientes al sector financiero se confeccionó a partir de la información proporcionada por las bases de datos en Internet de organizaciones como la Confederación de Cajas de Ahorro (CECA), la Asociación Española de Banca (AEB) y Unión Nacional de Cooperativas de Crédito (UNACC). A partir de ellas fue posible confeccionar un listado de 239 instituciones financieras, de las cuales 119 se contactaron. Respondieron el cuestionario 32 empresas del sector, lo que representa una tasa de 
respuesta del $26.89 \%$, respectivamente; no obstante, de la muestra obtenida en el sector financiero hubo que desechar dos de ellos debido a la falta de consistencia interna de los datos., por lo que al final sólo se utilizaron los 30 restantes sobre el total de la muestra de las instituciones del ramo.

La técnica de recolección de datos que se utilizó fue el cuestionario, diseñado específicamente para este estudio y fue enviado por correo postal y, a su vez, se ofreció la posibilidad de acceder a él en la página web: http://proyectocompetencias. esp.cc, creada para el presente estudio. Las personas contactadas para contestar el cuestionario fueron los responsables de las áreas de recursos humanos. Este trabajo de campo se llevó a cabo en el periodo entre el 1 de junio y el 5 de diciembre de 2004; adicionalmente, y debido al lapso ocurrido entre la recolección de datos para el cuestionario y la actualidad, durante el año 2010 se llevó a cabo un proceso de entrevistas telefónicas con una submuestra de las organizaciones que respondieron al cuestionario original, con el objetivo de comparar los datos entre los dos periodos, así como de conocer las motivaciones de la utilización o no de la gestión por competencias por parte de dichas empresas, y su evolución ocurrida en este periodo.

\section{Medición de variables}

Las variables empleadas en este estudio se derivan de la revisión de la literatura relacionada con temas de recursos humanos y, sobre todo, con la gestión por competencias. A continuación, se describen las variables empleadas:

Políticas de recursos humanos y competencias. En la primera parte del cuestionario se incorporaron las prácticas y políticas de RRHH que de acuerdo con la literatura, tanto teórica como empírica, tienen relación con la gestión por competencias. Asimismo, se incluyen algunas cuestiones para extraer información sobre el tipo de actores que participan en el proceso, el tipo de competencias que poseen, etc. (Boam y Sparrow, 1992; Boyatzis, 1982; CEOE, 2002; Dolan et al. 2003; Gick y Pallares, 1997; Goleman, 2002; Horton, 2000a, 2000b; HayGroup, 2005; LevyLeboyer, 1997; Llopart, 1997; Menéndez, 2001; Melián, 1995; Mitrani et al. 1992; Parry, 1996; Pereda y Berrocal, 2005; Rodríguez, 1999).

Técnicas para identificar competencias. Las preguntas que se incluyen en esta parte tienen por objeto conocer el tipo de técnicas y metodologías que más se utilizan en la identificación y evaluación de las competencias; estas preguntas fueron 
extraídas originalmente de los trabajos de Boam y Sparrow (1992), HayGroup (2005), Pereda y Berrocal (2001) y Mitrani et al. (1992), así como de Spencer y Spencer (1983).

Acepciones de competencias. Siguiendo la literatura sobre el tema (Boyatzis, 1982; Gick y Pallares, 1997; Horton, 2000ª Lévy-Leboyer, 1997; Llopart, 1997; Mirabile, 1997; Woodruffe, 1993), esta parte se incorporó para medir el posicionamiento terminológico, en cuanto a la forma en que se expresa y se entiende lo que es la gestión por competencias. Cabe aclarar que en la literatura, la acepción del término competencias es catalogado como polisémico y sugerente.

Nivel de complejidad en la implantación del sistema de gestión por competencias. Esta parte se diseñó para conocer el grado de dificultad que experimentan las empresas en la implantación de los modelos de competencias en relación con los procesos de recursos humanos. Se formularon cuatro preguntas en las que sólo una de ellas es de carácter ordinal y el resto de tipo nominal. Para el desarrollo de las preguntas se tomaron como principal referencia los trabajos de CEOE, 2002; Horton, 2000b y Menéndez, 2001.

Rendimiento empresarial. Esta parte tiende a medir los rendimientos de las empresas por medio de una escala de tipo nominal. Es de destacar que, según constata la literatura (De Saá y García, 2001; Flavián et al, 1998), no existe un acuerdo homologado entre los analistas acerca de cómo medir los resultados. Si bien existen diversas formas de medirlas, la opción desarrollada en el presente estudio contribuye a que el análisis no se viera influido por las opiniones referentes a un sólo año (en nuestro caso el 2004), en el que pudieran haber incidido cierto tipo de eventos extraordinarios.

\section{Resultados}

En este apartado se exponen los principales resultados del trabajo de campo relacionado con el nivel de implementación de la gestión por competencias y su relación con el rendimiento empresarial de las empresas del sector textil y las instituciones financieras.

Grado de implantación de la gestión por competencias en la empresa española

De acuerdo con los cuestionamientos planteados en este trabajo, en la pregunta de 
cuál es el grado de implementación en las empresas españolas, los resultados indican que de las 129 empresas del sector textil el 12\% optó por introducir modelos de competencias; mientras que de las 30 instituciones financieras que participaron en el estudio, el $43 \%$ tenía implementada esta técnica de recursos humanos. A continuación, en el cuadro 4 se presenta la información obtenida para ambos sectores, así como la información agregada para la totalidad de empresas analizadas.

\section{Cuadro 4}

\begin{tabular}{c|c|c|c}
\hline & \multicolumn{2}{|c|}{$\begin{array}{c}\text { Implementan el sistema de } \\
\text { gestión por competencias }\end{array}$} & $\begin{array}{c}\text { Empresas que } \\
\text { se encuentran } \\
\text { trabajando para } \\
\text { implementarla }\end{array}$ \\
\hline & Sí & No & \\
\hline $\begin{array}{c}\text { Sector } \\
\text { textil }\end{array}$ & $\begin{array}{c}(15 \\
\text { empresas }) \\
12 \%\end{array}$ & $\begin{array}{c}(113 \text { empresas }) \\
88 \%\end{array}$ & $14.9 \%$ \\
\hline $\begin{array}{c}\text { Sector } \\
\text { financiero }\end{array}$ & $\begin{array}{c}(13 \\
\text { empresas }) \\
43 \%\end{array}$ & $\begin{array}{c}(17 \text { empresas }) \\
57 \%\end{array}$ & $35.3 \%$ \\
\hline $\begin{array}{c}\text { Total de } \\
\text { empresas }\end{array}$ & 28 & 130 & \\
\hline
\end{tabular}

En primer lugar, los datos muestran que de las empresas que manifestaron no contar aún con un sistema de gestión por competencias (57\% de las empresas financieras y $88 \%$ de las textiles) al menos un $35.3 \%$ de las financieras y un $14.9 \%$ de las textiles afirmaron encontrarse trabajando para implementarla. En este sentido, las empresas que no tienen un sistema de gestión por competencias o que sólo lo tienen implementado en alguno de sus procesos de recursos humanos manifestaron que lo introducirían en un periodo no mayor a dos años.

Características de los procesos de implementación del sistema de gestión por competencias. La realidad de las características de las prácticas de gestión por competencias en la empresa española y su contrastación con la retórica que aparece en la literatura descriptiva muestra que los resultados relacionados con este trabajo son equiparables a los expuestos por Gick y Pallares (1997). Estos autores afirman que la utilización más común de la gestión por competencias de las empresas europeas analizadas está precisamente encaminada para apoyar el rendimiento de éstas a través de programas de formación; es decir, estos programas — desde la perspectiva de los citados autores- se basan en un proceso de definición de modelos idóneos para determinados puestos y, en consecuencia, se evalúa a los empleados con res- 
pecto a ese diseño preestablecido en el puesto de trabajo. En este sentido, el estudio realizado con las empresas españolas pone al descubierto que son precisamente las políticas de desempeño-rendimiento, reclutamiento y selección donde existe la mayor aplicación de la gestión por competencias, y la política de compensación es la menos adaptada para tal fin.

Agentes que participan en el modelo de gestión por competencias en las empresas. A partir de los datos obtenidos, se pudieron observar que en las empresas textiles los que más participan de este modelo de gestión son los altos directivos, seguidos por la línea directiva. En el caso de las instituciones financieras, éstas destinan este tipo de evaluación principalmente los empleados administrativos y los profesionales técnicos. En todo caso, los resultados de los estudios expuestos por Menéndez (2001), así como por Gick y Pallares (1997) establecen que siguiendo con el plan estratégico que se tenga implantado, tal y como se muestra para las instituciones financieras, se puede involucrar a otras categorías de empleados si se considera que es redituable. Es destacable, además, que los principales protagonistas en la implantación y desarrollo de los modelos de competencias en las empresas de este trabajo fueron básicamente los altos directivos y los responsables de recursos humanos con la participación, desde luego, de los expertos externos y la línea directiva, en el caso de las compañías textiles. Para las compañías financieras, los responsables de recursos humanos y los expertos externos superaron su participación en comparación con las empresas textiles, por lo que —en los resultados obtenidos en el caso de las empresas textiles - son análogos a los mostrados por Menéndez (2001) cuando en ambos se menciona la participación de los altos directivos como los principales promotores de los modelos de competencias.

Técnicas utilizadas para identificar las competencias. Asimismo, se pone en evidencia que las empresas analizadas en mayor medida prefirieron utilizar distintos procedimientos y técnicas para identificar y diseñar sus modelos de competencias. Entre las empresas textiles se destaca, la técnica de Discusión en grupos y la $\mathrm{Ob}$ servación directa; mientras que entre las instituciones financieras, los métodos más empleados fueron la Entrevista en profundidad y la Autoevaluación de empleados. En este sentido, los resultados anteriormente mostrados específicamente para las compañías textiles son equiparables a los expuestos por Gick y Pallares (1997), dado que estos autores en un epígrafe anterior de esta investigación habían señalado que la técnica de Discusión en grupos, o grupos de trabajo, había sido el principal instrumento por las empresas europeas para identificar, medir o evaluar las competencias de los trabajadores. 
En lo relacionado a los listados de competencias, el resultado en las compañías textiles señala que las empresas participantes han visualizado como principales competencias, en orden de importancia: Pensamiento analítico, Pensamiento estratégico y Dirección de personas, Orientación al logro y Orientación al cliente; en contraste, las financieras se decantaron preferiblemente por la Dirección y desarrollo de persona, Orientación al logro y Pensamiento estratégico, específicamente para evaluar a sus directivos. Para las demás categorías de empleados, las compañías financieras recurrieron principalmente a: Trabajo en equipo, Orientación al cliente, Identificación con la compañía, Flexibilidad y, por último, Pensamiento analítico. No obstante, los resultados expresados por Gick y Pallares (1997) situaban a la competencia de Comunicación abierta en primer lugar, seguida de la Orientación al logro y del Trabajo en equipo, lo cual como puede observarse, en relación con la segunda y tercera competencias del estudio aludido, son afines a la preferencia que las instituciones financieras manifestaron en referencia con la competencia de logro y trabajo en equipo.

Acepciones de competencias. No menos importante es la forma en que las compañías textiles y financieras entienden lo que es la gestión por competencias. Entre las empresas textiles, la definición de esta técnica estuvo relacionada a la consideración de las competencias como repertorios de comportamientos, identificándose así con la visión de la escuela francesa de la gestión por competencias. En forma distinta, las empresas financieras entienden que las competencias son características subyacentes, tal y como lo expresan los autores de la escuela americana de competencias y como lo muestran Gick y Pallares (1997) y Menéndez (2001) en sus respectivos trabajos.

Nivel de complejidad en la implantación del modelo de gestión por competencias. Finalmente, a la luz de los resultados obtenidos en este trabajo, se expone que la complejidad de implementar esta técnica de recursos humanos, en términos globales, fue catalogada en la mayoría de los casos analizados en un grado medio. Aunque es de destacar que las instituciones financieras que no tienen implementado un sistema de competencias (29\% de ellas) consideraron que la gestión por competencias es costosa y $18 \%$ señaló que es difícil de implementar. Incluso, en cuanto al uso de las técnicas específicas para identificar y analizar las competencias individuales, las compañías investigadas en términos generales consideraron que el uso de éstas en realidad presentaron gran complejidad a la hora de ser manipuladas. Se encontró, por tanto, una similitud con los datos presentados por Me- 
néndez (2001); este autor señaló que este sistema, con relación al estudio de casos con empresas de alta rentabilidad ubicadas en España, puso al descubierto que al momento de implementar dicho sistema de competencias originó procesos costosos y prolongados, lo que obligó a las empresas mencionadas a reformular dichos procedimientos.

\section{Efecto del rendimiento de las empresas en la implantación del modelo de ges- tión por competencias}

Por otra parte, en cuanto a la relación del rendimiento de las empresas con la implantación del modelo de gestión por competencias se destaca que — de acuerdo con los distintos contrastes llevados a cabo con las estadísticas utilizadas- existe una concordancia importante entre la capacidad económica de las empresas investigadas (con base en los sectores con altos y bajos rendimientos) y la implantación de gestión por competencias.

En el cuadro 5 se observa que el grado de implantación es mucho mayor en el sector financiero que en el textil; es decir, hay una diferencia significativa entre las proporciones de las empresas investigadas por el valor expresado en $z$.

\section{Cuadro 5}

Cálculo del error típico de las proporciones globales de las empresas textiles y financieras

\begin{tabular}{|c|c|c|c|c|c|c|}
\hline \multicolumn{7}{|c|}{ Diferencia entre proporciones } \\
\hline \multicolumn{2}{|c|}{$\begin{array}{l}\text { Cálculo del error típico de las proporciones de las empresas } \\
\text { textiles y financieras que exclusivamente manifestaron que si } \\
\text { tenían competencias }\end{array}$} & Categoría & $\mathbf{N}$ & P1 & Q2 & $\begin{array}{l}\text { Valor } \\
\text { típico }\end{array}$ \\
\hline \multirow{3}{*}{ ¿Tiene sistema GC? } & $\begin{array}{c}\text { Grupo } 1 \\
\text { (FIN) }\end{array}$ & Sí & 30 & .43 & .57 & 3.87 (a) \\
\hline & Grupo 2 (TEX) & Sí & 129 & .12 & .88 & \\
\hline & Total & & 159 & P1 & Q2 & \\
\hline
\end{tabular}

Cálculo del error típico de las proporciones de los rendimientos globales de las empresas textiles y financieras que si tienen gestión por competencias

\begin{tabular}{c|c|c|c|c|c|c}
\hline ¿Tiene sistema GC? & Grupo 1 (GL) & Sí & 28 & .61 & .39 & $4.81 \mathrm{a}$ \\
\hline & Grupo 2 (GL) & No & 131 & .16 & .84 & \\
\hline & Total & & 159 & P1 & Q2 & \\
\hline
\end{tabular}

a Basado en la aproximación Z. Significativo a partir de 1,65

(FIN) sector financiero

(TEX) sector textil

(GL) Muestra conjunta o global 
A partir de estos resultados se puede afirmar que los sectores empresariales con mejores rendimientos tienen una proporción de empresas con sistemas de gestión por competencias mayor que los sectores con rendimientos desfavorables.

En el cuadro 6 los contrastes realizados en la prueba binomial en forma individual para los sectores estudiados no mostraron valores estadísticamente significativos. Sin embargo, cuando se efectuó el contraste de las variables estudiadas en forma conjunta, los resultados revelaron una probabilidad mayor de poseer un sistema de gestión por competencias cuando las empresas tienen mayores rendimientos.

\section{Cuadro 6}

\section{Prueba binomial para mayores y menores rendimientos de las empresas textiles $y$ financieras}

\begin{tabular}{|c|c|c|c|c|c|c|c|c|c|c|c|c|c|c|}
\hline \multicolumn{15}{|c|}{ Prueba binomial } \\
\hline \multicolumn{2}{|c|}{$\begin{array}{c}\text { Mayores } \\
\text { rendimientos }\end{array}$} & \multirow{2}{*}{\begin{tabular}{|c|}
$\begin{array}{c}\text { Catego- } \\
\text { ría }\end{array}$ \\
Sí
\end{tabular}} & \multirow{2}{*}{\begin{tabular}{|c|}
$\begin{array}{c}\text { TEX } \\
(\mathbf{N})\end{array}$ \\
4
\end{tabular}} & \multirow{2}{*}{$\begin{array}{c}\text { FIN } \\
(\mathbf{N}) \\
13\end{array}$} & \multirow{2}{*}{\begin{tabular}{|l|}
$\mathbf{G L}$ \\
$(\mathbf{N})$
\end{tabular}} & \multicolumn{3}{|c|}{$\begin{array}{c}\text { Proporción } \\
\text { observada }\end{array}$} & \multicolumn{3}{|c|}{$\begin{array}{c}\text { Proporción } \\
\text { de prueba }\end{array}$} & \multicolumn{3}{|c|}{$\begin{array}{l}\text { Sig. exacta } \\
\text { (unilateral) }\end{array}$} \\
\hline \multirow{3}{*}{$\begin{array}{c}\text { ¿Tiene } \\
\text { sistema GC? }\end{array}$} & $\begin{array}{c}\text { Grupo } \\
1\end{array}$ & & & & & .307692 & .520 & .447368 . & .116000 & 0.433 & .176000 & .055 & .248 & 3.000 \\
\hline & \begin{tabular}{|c|} 
Grupo \\
2
\end{tabular} & No & 9 & 12 & 21 & .692308 & .480 & .552632 & & & & & & \\
\hline & Total & & 13 & 25 & 38 & 1.000000 & 1.000 & 1.000000 & & & & & & \\
\hline \multicolumn{15}{|l|}{\begin{tabular}{c|} 
Menores \\
rendimientos
\end{tabular}} \\
\hline \multirow[t]{2}{*}{$\begin{array}{c}\text { ¿Tiene } \\
\text { sistema GC? }\end{array}$} & $\begin{array}{c}\text { Grupo } \\
1\end{array}$ & No & 29 & 5 & 30 & .966667 & 1.000 & .967742 & .116000 & .433 & .176000 & .000 & .015 & 5.000 \\
\hline & $\begin{array}{c}\text { Grupo } \\
2\end{array}$ & Sí & 1 & & 1 & .033333 & & .032258 & & & & & & \\
\hline \multicolumn{2}{|r|}{ Total } & & 30 & 5 & 31 & 1,000000 & 1.000 & 1.000000 & & & & & & \\
\hline
\end{tabular}

Estos resultados indican que dentro de las empresas que tienen mayores rendimientos existe una mayor proporción de empresas con modelos de gestión por competencias implantados con respecto al conjunto de todas ellas.

Ahora bien, en la misma dirección de los hallazgos de este trabajo, un 26\% de las empresas textiles y un $100 \%$ de las empresas financieras mostraron los valores más elevados de rendimiento. Pese a que los valores en forma individual de cada uno de los sectores analizados no son estadísticamente significativos, muestran que a medida que incrementa el nivel de ingresos en las empresas investigadas los 
porcentajes de las empresas que poseen gestión por competencias es mayor con respecto de las que no tienen este sistema. Asimismo, los contrastes efectuados de forma conjunta (véase cuadro 7) señalan la existencia de una relación, aunque moderada, por haber obtenido valores ligeramente superiores a $40 \%$ entre las variables de rendimiento de la organización y la implantación de gestión por competencias. Finalmente, los valores estadísticos como Tau de Goodman y Kruskal y Coeficiente de Incertidumbre de acuerdo con su lógica direccional, aun cuando muestran valores muy reducidos, también confirman la existencia de una relación entre las variables estudiadas. En el mismo cuadro 7, el valor expresado en el Chicuadrado indica la existencia de una correlación débil entre la variable dicotómica de gestión por competencias y el rendimiento de la organización.

\section{Cuadro 7}

\section{Prueba del Chi-cuadrado, simétricas y direccionales}

\begin{tabular}{|c|c|c|c|c|c|c|}
\hline Muestra & Prueba estadística & Dependiente & Valor & GL & $\begin{array}{c}\text { Razón de } \\
\text { verosimilitud }\end{array}$ & $\begin{array}{c}\text { No. de casos } \\
\text { válidos }\end{array}$ \\
\hline Textil (TEX) & Chi-cuadrado & & $3.537(\mathrm{NS})$ & 1 & $5.980(\mathrm{NS})$ & 104 \\
\hline Financiera (FIN) & Chi-cuadrado & & .791 (NS) & 1 & 1.162 (NS) & 30 \\
\hline $\begin{array}{l}\text { Muestra global } \\
\text { (GL) }\end{array}$ & Chi-cuadrado & & $26.757 * *$ & 3 & $25.070 * *$ & 159 \\
\hline $\begin{array}{l}\text { Muestra global } \\
\text { (GL) }\end{array}$ & Phi & & $.410 * *$ & & & 159 \\
\hline $\begin{array}{l}\text { Muestra global } \\
\text { (GL) }\end{array}$ & V de Cramer & & $.410^{* *}$ & & & 159 \\
\hline $\begin{array}{l}\text { Muestra global } \\
\text { (GL) }\end{array}$ & $\begin{array}{c}\text { Coeficiente de } \\
\text { contingencia }\end{array}$ & & $.380 * *$ & & & 159 \\
\hline \multirow[b]{2}{*}{$\begin{array}{c}\text { Muestra global } \\
(\mathrm{GL})\end{array}$} & \multirow{3}{*}{ Lambda } & Simétrica & $.071(\mathrm{NS})$ & & & 159 \\
\hline & & ¿Tiene sistema GC? & .000 (NS) & & & \\
\hline $\begin{array}{l}\text { Muestra global } \\
\text { (GL) }\end{array}$ & & \begin{tabular}{|c|}
$\begin{array}{c}\text { Rendimiento de la } \\
\text { organización }\end{array}$ \\
\end{tabular} & .095 & & & \\
\hline \multirow[b]{3}{*}{$\begin{array}{l}\text { Muestra global } \\
\text { (GL) }\end{array}$} & \multirow[b]{3}{*}{$\begin{array}{c}\text { Tau de Goodman y } \\
\text { Kruskal }\end{array}$} & Simétrica & & & & 159 \\
\hline & & ¿Tiene sistema GC? & $.168^{* *}$ & & & \\
\hline & & $\begin{array}{l}\text { Rendimiento de la } \\
\text { organización }\end{array}$ & .063 & & & \\
\hline $\begin{array}{l}\text { Muestra global } \\
(\mathrm{GL})\end{array}$ & \multirow{3}{*}{$\begin{array}{l}\text { Coeficiente de } \\
\text { incertidumbre }\end{array}$} & Simétrica & $.094 * *$ & & & 159 \\
\hline $\begin{array}{c}\text { Muestra global } \\
\text { (GL) }\end{array}$ & & ¿Tiene sistema GC? & $.169^{* *}$ & & & \\
\hline $\begin{array}{l}\text { Muestra global } \\
(\mathrm{GL})\end{array}$ & & \begin{tabular}{|c|}
$\begin{array}{c}\text { Rendimiento de la } \\
\text { organización }\end{array}$ \\
\end{tabular} & .065 & & & \\
\hline
\end{tabular}

financiera 
A partir de los resultados observados en el cuadro 7, se puede establecer que las empresas con menores rendimientos cuentan con una mayor probabilidad de no tener gestión por competencias. En este sentido, se consideraron las diferencias entre las proporciones de los valores observados y esperados en la variable dicotómica; es decir, el valor de las proporciones de las empresas que tienen o no competencias con respecto a los porcentajes obtenidos en las categorías de menores rendimientos. El resultado de dicha prueba es muy significativo, pues indica que a medida que los rendimientos decrecen se incrementa la probabilidad de no tener un sistema basado en competencias (véase el cuadro 6), confirmando nuestra suposición de que estas empresas están ocupadas en otros asuntos más apremiantes que no son la introducción e implantación de un sistema, lo cual - aunque con gran potencial - necesitará tiempo y dinero antes de que revierta en resultados para la empresa.

Confirmando estos resultados, las entrevistas realizadas más recientemente ilustran casos en los cuales la lógica propuesta se ve reforzada. Así, continuamos encontrando más empresas del sector bancario que del sector textil que continúan teniendo un sistema de gestión por competencias.

Más interesante es el hecho de que algunas instituciones del sector bancario — que en este periodo se vieron sujetas a reestructuraciones (en un caso) y a fusiones (en otro caso) debido a la actual situación de crisis - perdieron en este tránsito algunos de los aspectos de su sistema de gestión por competencias. Así, en el caso de fusión, no solamente se eliminó el sistema, sino también la propia sección de desarrollo del departamento de recursos humanos que se había encargado de implantarla. En el otro caso, se continúan utilizando las competencias identificadas para orientar los comportamientos de los empleados, pero éstas dejaron de estar vinculadas al sistema de retribución, demostrando en este caso una eliminación parcial del sistema de gestión por competencias cuando la situación económica de la empresa empeora.

\section{Conclusiones y discusión}

De acuerdo con la revisión de la literatura y los objetivos enmarcados en el diseño y análisis de los datos de esta investigación, se desprenden las siguientes conclusiones: 
En respuesta a la primera pregunta que se plantea: ¿qué grado de implantación tiene la gestión por competencias en la empresa española? Los resultados alcanzados muestran que existe una mayor implementación de la gestión por competencias en las empresas financieras que las textiles (12\% textiles y $43 \%$ financieras). Sin embargo, un gran porcentaje de las empresas de ambos sectores que manifestaron no contar con una gestión por competencias se encontraban en proceso de introducirla en sus recursos humanos en un periodo máximo de dos años (véase el cuadro 4). Otro aspecto también destacable es la diversidad de técnicas para identificar y evaluar las competencias de los empleados que principalmente utilizan las empresas de ambos sectores, tales como: discusión en grupos, observación directa, entrevista en profundidad y la autoevaluación de empleados. Asimismo, el estudio realizado con las empresas españolas pone al descubierto que son precisamente las políticas de desempeño-rendimiento, reclutamiento y selección donde existe la mayor aplicación de la gestión por competencias y la política de compensación es la menos adaptada para tal fin. En definitiva, los resultados de las entrevistas llevadas a cabo en 2010 con el objetivo de comparar los datos entre los dos periodos confirman los hallazgos de esta investigación, excepto por algunas restructuraciones relacionadas con fusiones llevadas a cabo en el sector financiero que influyeron en que algunas instituciones desvincularan la gestión por competencias de los sistemas de retribución.

En respuesta a la segunda pregunta que plantea: ¿el rendimiento de las empresas, en qué medida afecta a la implantación del modelo de gestión por competencias? Los hallazgos obtenidos indican que los sectores empresariales con buenos resultados muestran una tendencia a tener gestión por competencias, dado que en la prueba de diferencia de proporciones entre ambos sectores de estudio la diferencia resultante fue considerable; por ello, partiendo del análisis de sectores con resultados antagónicos se puede establecer que los sectores empresariales con mejores rendimientos tienen una proporción de empresas con sistemas de gestión por competencias mayor que los sectores con rendimientos desfavorables (véase el cuadro 5).

Por otro lado, los datos alcanzados a partir del análisis conjunto de las empresas investigadas muestran que las empresas con mayores rendimientos tienen más probabilidad de tener gestión por competencias; por lo tanto, los resultados indican que no existe evidencia para aseverar que las variables de gestión por competencias y el rendimiento empresarial son independientes (véase los cuadros 6 y 7). Así, de acuerdo con estos resultados se propone que dentro de las empresas que 
tienen mayores rendimientos, es mayor la proporción de las que tienen gestión por competencias que considerando el conjunto de todas ellas.

Otros resultados obtenidos, como las diferencias observadas entre las proporciones de la prueba binomial (véase el cuadro 6), sugieren que dentro de las empresas que tienen menores rendimientos es mayor la proporción de las que no tienen competencias con respecto de las que sí.

Consecuentemente, estos resultados pueden indicar que la implementación de gestión por competencias tiene más aceptación en el sector financiero que en el textil, entre otras cosas, porque las condiciones organizacionales en todos los sentidos favorecen a las instituciones financieras en aspectos como un compromiso para mejorar la calidad de su servicio, los procesos de liberalización y competencia, incremento en la profesionalización de su personal, en concordancia con De Saá y García, (2001); Balcells, (1993) y Armstrong, (1999).

Tomando como base las evidencias de este estudio, los datos favorecen a lo dicho por autores como Menéndez (2001), Gick y Pallares (1997), Spencer y Spencer (1993), Salgado y Moscoso (2001) y Pereda y Berrocal (2005) con respecto a que la implementación de la gestión por competencias es una técnica que requiere una gran estructura organizativa para gestionar el modelo debido a la gran variedad de técnicas que se utilizan para su análisis — tales como las entrevistas en profundidad, la entrevista de incidentes críticos, así como todas las pruebas que conforman los Assessment Centers (Centros de evaluación profesional)—, las cuales pueden incrementar los costos de operación de forma considerable, pues se requieren especialistas en la materia para aplicarlas y en muchos de los casos cada análisis consume un tiempo considerable.

De igual forma, en esta investigación se pueden considerar importantes implicaciones relacionadas en casos concretos. Desde un enfoque práctico, las empresas investigadas pueden tener una visión de algunas ventajas e inconvenientes de la gestión por competencias dado que es necesario tener evidencias sobre las implicaciones científicas y laborales y, sobre todo, organizacionales de la gestión por competencias. Así, las empresas podrán tener referentes sobre las condiciones organizativas y económicas que se requieren para implementar esta técnica de recursos humanos. En suma, se debe analizar si las condiciones económicas y la formalización de las políticas de recursos humanos están en condiciones para optar por un modelo de competencias. 
Finalmente, cabe aclarar que existe plena conciencia que realizar este trabajo provocó afrontar diversas limitaciones, que pueden ser superadas en futuras investigaciones. Con relación a la muestra no es posible generalizar los resultados alcanzados en este estudio a toda la población de los sectores investigados. Esto fue debido a que el universo de trabajo de las compañías textiles comprendió exclusivamente las que tenían de 40 empleados en adelante, descartando así a la Pyme. Igualmente para las empresas del sector financiero, dado que sólo se analizaron tres subsectores de este ramo: bancos, cajas de ahorro y cajas rurales, por lo que los resultados sólo pueden ser extrapolables a estas últimas; máxime cuando ellos están compuestos por una muestra de 30 instituciones, que si bien en términos de recursos humanos y monetarios es representativo, siempre será mejor tener el mayor número de empresas posible. Además, sería necesaria la aplicación y ampliación del mismo en otros sectores empresariales para contrastar los resultados alcanzados de esta investigación en otros contextos.

Destacamos el hecho de que la falta de consistencia y publicidad en los ratios de rentabilidad económica (corporativa) o financiera influyó para que no se tomaran en cuenta a la hora de medir los resultados empresariales, especialmente por la falta de información de las empresas textiles dadas las precarias condiciones económicas que aquejan a dicho sector. Otra limitante para la realización de este trabajo está relacionada con la reducción del número de preguntas en el cuestionario en aras de alcanzar más respuestas para la medición de variables.

Como conclusión cabe admitir que los medios analíticos son limitados para establecer una relación causa-efecto; sin embargo, las pruebas que se han realizado en este estudio son similares a las que otros estudios de recursos humanos utilizan para argumentar la relación contraria. El estudio ha conseguido, por tanto, cuestionar la presunción que de entrada se permite a muchos estudios que pretenden relacionar la introducción de una técnica o política con una mejora de los resultados empresariales. Queda abierta, pues, la posibilidad de que gestión por competencias y mejores rendimientos empresariales puedan ser tanto la causa como la consecuencia del otro. 


\section{Referencias}

Acosta, V. (1997). Las técnicas para desarrollar un Assessment Centre y su adecuación para la evaluación de diferentes competencias. Capital Humanoe (105): 6-12.

Ahmad, S. y R. Schroeder (2002). The importance of recruitment and selection process for sustainability of total quality management. International Journal of Quality \& Reliability Management 19 (5): 540-550.

Alamillo, M. y F. Villamor. (2002). Modelo de gestión por competencias. Aedipe (21): 3-12.

Alles, M. (2006). Selección por competencias. Buenos Aires: Ediciones Granica.

Anguera, M. T. (1985). Metodología de la observación en las ciencias humanas. Madrid: Ediciones Cátedra.

Armstrong, M. (1999). Employee reward. Londres: Chartered Institute of Personnel and Development.

(2010). Armstrong's Hand book of reward management practice: improving performance through reward. Londres: Chartered Institute of Personnel and Development.

Arthur, J. B. (1994). Effects of human resource systems on manufacturing performance and turnover. Academy of Management Journal 37 (3): 670-687.

Atkins, P. y R. Wood (2002). Self-versus others' ratings as predictors of assessment center ratings: validation evidence for $360^{\circ}$ - degree feedback programs. Personnel Psychology (55): 871-904.

Balcells, J. (1993). Los nuevos requisitos de la formación del personal para las entidades bancarias. Papeles de Economía Española (54): 112-115.

Benicio de Mello, S., F. R. Bezerra y F. Gomes de Paiva (2007). Competéncias empreededoras Do Dirigente De Empresa De Base Tecnológica: Um Caso Empresarial de Sucesso. Revista de Administracae Mackenzie 8 (3): 50-76. 
Birdir, K. y T. E. Pearson (2000). Research chef's competencies: a Delphi Approach. International Journal of Contemporary Hospitality Management 12 (3): 205-209.

Blanco, A. (2007). Trabajadores competentes: introducción y reflexiones sobre la gestión de recursos humanos por competencias. Madrid: ESIC.

Boam, R. y P. Sparrow (1992). Designing and Achieving Competency: A competency-Based Approach to Developing People and Organizations. Inglaterra: McGraw-Hill.

BOE (2002). Ley Orgánica 5/2002 de las cualificaciones y de la formación profesional. de 19 de junio (147).

Bohne, P. (2002). Achieving Career Goals through Self-evaluation. Healthcare Financial Management, september: 100-102.

Boyatzis, R. (1982). The Competent Manager. New York: John Wiley and Sons.

Brophy, M. y T. Kiely (2002). Competencies: a new sector. Journal European Industrial Training 26 (2-3-4): 165-176.

Brotherton, B. y S. Watson (2001). Licensed house manager skills/competences and the management development process in Bass Taverns. Human Resource Development International 4 (4): 521-542.

Burchell, H. y S. Westmoreland (1999). Relations between competence-based education and student reflection on practice: a UK case study of initial teacher training. International Journal of Training and Development 3 (2): 156-166.

Cámara de Comercio de Barcelona (2010). Disponible en: http://blog.infojobs. net/archives/0000/0014/Presentacion_OBSERVATORIO_DE_COMPETENCIAS.PDF

Caveda, F. J. L. (1997). Manual del director de recursos humanos. Madrid: CIS. 
Carneiro, A. M. M., R. Valle y Coelho Jr. (2003). Conceitos de qualificação e de competências retrospectiva e novas abordagens. $O$ conhecimento em ação: reestruturação produtiva e novas competências para o trabalho. R. Valle (Org.). Rio de Janeiro: Relume \& Dumará: 4-28.

CEDEFOP (2010). ¿Vamos por buen camino? Desajuste de competencias en Europa. Nota informativa. Centro Europeo para el Desarrollo de la Formación Profesional, junio: 1-4.

Confederación Española de Organizaciones Empresariales (CEOE) (2002). La gestión por competencias en España: Informe para el observatorio europeo de gestión por competencias. España: Departamento de Relaciones Laborales.

Claver, C.E., G.L. Gascó y T.J. Llopis (1996). Los recursos humanos en la empresa: un enfoque directivo. Madrid: Editorial Civitas.

Cornford, T. y J. Aghanasou (1995). Developing expertise through training. Industrial Comercial Training 27 (2): 10-18.

Cowling, A., K. Newman y S. Leigh (1999). Developing a competency framework to support training in evidence based healthcare. International Journal of Health 12 (4): 149-159.

Craig, S. (1992). Using competencies in career development. Designing and achieving competency: a competency based approach to developing people and organizations. R. Boam y P. Sparrow (eds.). Londres: McGraw-Hill: 112127.

Cubeiro, J. C. y G. Fernández (1998). Competencias 4.0. Capital Humano mayo (111): 48-50.

Davenport, T. (2000). Capital humano: creando ventajas competitivas a través de las personas. Barcelona: Gestión 2000.

De Ansorena, A. (1999): 15 pasos para la selección de personal con éxito: métodos e instrumentos. Barcelona: Paidós. 
De Saá, P. y J. M. García (2001). El sistema de recursos humanos y el desarrollo de capacidades organizativas: una aplicación empírica en el sector de las cajas de ahorro españolas. Cuadernos de Economía y Dirección de Empresas (8): 109-137.

Dolan, S. L., C. R. Valle, E. S. Jackson y S. R. Schuler (2003). La gestión de los recursos humanos: preparando profesionales para el siglo XXI. Madrid: McGraw Hill.

Duverger, M. (1996). Métodos de las ciencias sociales. Barcelona: Ariel.

Espinoza, J. (1994). La metodología del Assessment Center, paso a paso. Capital Humano noviembre, suplemento (72): 36-40.

Fernández, J. (2005). Gestión por competencias: Un modelo estratégico para la dirección de recursos humanos. Madrid: Prentice Hall.

Fielding, N. (1988). Competence and culture in the police. Sociology 22 (1): 45-64.

Flanagan, C.J. (1954). The critical incident tecnique. Psycological bolletin 51 (4): 327-357.

Flavián, C., L. Fuentes e Y. Polo (1998). Comportamiento estratégico y rivalidad entre cajas de ahorro. Empresa y economía institucional. ACEDE: Las Palmas de Gran Canaria.

Gick, A. y T. Pallares (1997). Las competencias en el trabajo: ¿Qué está pasando en Europa? Capital Humano, abril (99): 43-48.

Goleman, D. (2002). La práctica de la inteligencia emocional. Barcelona: Kairós. (2003). La inteligencia emocional. México: Ediciones B. (2004). El líder resonante crea más. Barcelona: Random House Mondadori.

Gómez, G. y J.R. Pin (1994). Dirigir es educar. Madrid: McGraw-Hill. 
Grant, R. (1995). Dirección estratégica, Madrid: Civitas.

Green, F. (2000). The impact of company human resource policies on social skills: implications for training sponsorship, quit rates and efficiency wages. Scottish Journal of Political Economy 47 (3): 251-272.

Haddad, W.D. (1997). La globalización de la economía: repercusiones en la educación y en la formación de competencias. Perspectivas 27 (1): 33-40.

Hansson, B. (2001). Competency models: are self-perceptions accurate enough? Journal of European Industrial Training 35 (9): 428-441.

Hart, C., A. Harrington y J.L. Clarke (1999). Retailer and student perceptions of competence development. International Journal of Retail \& Distribution Management 27 (9): 362-373.

Hay Group (1996). Las competencias: clave para una gestión integrada de los recursos humanos. Bilbao: Ediciones Deusto.

(2005). Las competencias: clave para una gestión integrada de los recursos humanos, Barcelona: Ediciones Deusto.

Hellriegel D., S. Jackson y J. Slocum (2005). Administración: un enfoque basado en competencias, México: Thomson.

Hoffmann, T. (1999). The meanings of competency. Journal of European Industrial Training 23 (6): 275-286.

Holmes, L. (1995). HRM and the irresistible rise of the discourse of competence. Personnel Review 24 (4): 34-49.

Horton, S. (2000a). Introduction-the competency movement: Its origins and impact on the public sector. The International Journal of Public Sector Management 13 (4): 306-318.

(2000b). Competency management in the british civil service. The International Journal of Public Sector Management 13 (4): 354-368. 
Huselid, M.A. (1995). The Impact of Human Resource Management Practices on Turnover, Productivity, and Corporate Financial Performance. Academy of Management Journal 38 (3): 635-672.

Joiner, D. (2002). Assessment Centers: What's New? Public Personnel Management 31 (2): 179-185.

Jordan, J. y S. Cartwright (1998). Selecting expatriate managers: key traits and competencies. Leadership \& Organization Development Journal 19 (2): 8996.

Kamoche, K. (1997). Competence-creation in the African public sector. International Journal of Public Sector Management 10 (4): 268-278.

Kelly, G. A. (1955). A theory of personality. The psychology of personal constructs. New York: Norton.

Kavitha, S.F., M. Vasugi y S. Murgadoss (2010). An Empirical Study on Employee core competencies A Proven Tool for an Organizations Success. Interdisciplinary Journal of Contemporary Research in Business 2 (8): 120-132.

Lado, A. A. y M. Wilson (1994). Human Resource Systems and Sustained Competitive Advantage: A competency-based perspective. Academy of Management Review 19 (4): 699-727.

Le Boterf, G. (1991). Ingeniería y evaluación de los planes de formación. Barcelona: Ediciones Deusto.

(1998). Évaluer les compétences Quels jugements? Quels critéres? Quelles instances? Education Permanente (135): 143-151. (2001). Ingeniería de las competencias, Barcelona: Gestión 2000.

Levy-Leboyer, C. (1997). Gestión de las competencias. Barcelona: Gestión 2000. (2000). Feedback de 360 . Barcelona: Gestión 2000. 
Llopart, P. X. (1997). La gestión de los recursos humanos en base a competencias, tesis doctoral, Departamento de Economía y Organización de Empresas, $\mathrm{UAB}$, Barcelona.

Lysaght, R. y J. Altschuld (2000). Beyond initial certification: the assessment and maintenance of competency in professions. Evaluation and Program Planning (23): 95-104.

Macduffie, J. P. (1995). Human resource bundles and manufacturing performance: organizational logic and flexible production systems in the world auto industry. Industrial and Labor Relations Review 48 (2): 197-221.

Malasia, S. Ch. y W. Khairuzzaman (2008). Human Resource Competencies: A study of the HR professionals in manufacturing firms in Malaysia. International Management Review 4 (2): 65-76.

Mandon, N. (1990). Un exemple de description des actités et des compétences professionnelles: l'empleoi-tipe secrétaire de vente. Les analyses du Travail: Enjeux et formes: 153-159.

Maurer, T., D. Mitchell y F. Barbeite (2002). Predictors of attitudes toward a 360degree feedback system and involvement in post-feedback management develppment activity. Journal of Occupational and Organizational Psychology (75): 87-107.

McClelland, C. D. (1973). Testing for competence rather than for intelligence. American psychologist, january: 1-15.

McLagan, P. (1997). Competencies: the next generation. Training \& Development may: 40-47.

Melián, S. (1995). La selección de personal: propuesta metodológica y validación empírica, tesis doctoral, Departamento de Economía de Empresas, Universidad de Las Palmas de Gran Canaria.

Menéndez, V.J. (2001). Gestión por competencias en España: Reflexiones desde el Observatorio Europeo de Gestión por Competencias. Aedipe (19): 30-45. 
Merlane, J.C. (1994). Reclutamiento y gestión de las competencias estratégicas. Capital Humano enero (63): 47-50.

Mertens, L. (1997). Sistemas de competencia laboral: surgimiento y modelos. Formación basada en competencia laboral: situación actual y perspectivas. Guanajuato: CINTERFOR.

y R. Wilde (2003). Aprendizaje Organizacional y Competencia Laboral. La Experiencia de las Naciones Unidas Grupo de azucareros en México. Reformas Económicas y Formación. Montevideo: Cinterfor /OIT.

Mirabile, R. J. (1997). Everything You Wanted to Know About Competency Modeling. Training \& Development: 73-77.

Mitchell, V. (1991). The Delphi Technique: an exposition and application. Techonology Analysis \& Strategic Management 3 (4): 333-358.

Mitrani, A., M. D. Murray e I. Suárez (1992). Las competencias: clave para una gestión integrada de los recursos humanos. Bilbao: Ediciones Deusto.

Moloney, K. (2001). Las entrevistas de análisis del comportamiento y los marcos de competencias. Aedipe, marzo (16): 39-44.

Olaz, A. (1998). La entrevista en profundidad como herramienta en proyectos de investigación. Capital Humano suplemento selección de personal, noviembre (116): 18-32.

Parry, S. B. (1996). The Quest for Competences. Training 33 (7): 48-56.

Pascoal, M., J. Montanha y C. Vercesi (2008). Management by competencies in small companies at the APL of caps of Apuracarana's PR City. Its understanding and practices in confrontation with the theoretical perspectives. $R e$ vista de Administracae Mackenzie 19 (8): 17-38.

Pereda, S. y F. Berrocal (1999). Gestión de recursos humanos por competencias. Madrid: Centro de Estudios Ramón Areces. 
(2005). Técnicas de gestión de recursos humanos por competencia. Madrid: Editorial Centro de Estudios Ramón Areces.

Peretti, J. (1997). Todos somos directores de recursos humanos. Barcelona: Gestión 2000/Aedipe.

Pérez, L. J. (1997). Qué son las competencias. Estudios Empresariales 3 (95):1015.

Pfeffer, J. (1994). Competitive Advantage Trough People. California Management Review winter: 9-28.

Porret, M. (2008). Recursos humanos: dirigir y gestionar personas en las organizaciones. Madrid: ESIC.

Prieto, J. M. (1997). Prologo. Gestión de las competencias: cómo analizarlas, cómo evaluarlas, cómo desarrollarlas. C. Lévy-Leboyer. Barcelona: Gestión 2000.

Puchol, L. (2007). Dirección y gestión de recursos humanos, Madrid: Díaz de Santos.

Richards, J. y C. Curran (2002). Oracles on "Advertising": searching for a definition. Journal of Advertising XXXI (2): 63-77.

Rodríguez, M. y U. Bustamante (2008). Desarrollo de competencias para el desarrollo ético-gerencial: Un enfoque de responsabilidad. Cuadernos de Administración 21 (35): 205-228.

Rodríguez, T. N. (1999). Selección efectiva de personal basada en competencias. XXVII Congreso Internacional de Psicología, Caracas, Venezuela. Disponible en: http://www.abacolombia.org.co/organizaciones/selección.htm

Rosenfeld, V. (1999). The value of Care national Vocational Qualifications: what impact do NVQs have on Care organizations in Hertfordshire? International Journal of Training and Development 3 (2): 142-155. 
Salgado, J. y S. Moscoso (2001). Entrevista conductual estructurada de selección de personal. Madrid: Pirámide.

Sandberg, J. (1995). Are phenomenographic results reliable? Nordisk Pedagogik (15): 156-164.

(2000). Understanding Human Competency at Work: An interpretative approach. Academy of Management Journal 43 (1): 9-25.

Spencer, L., D. McClelland y S. Spencer (1994). Competency Assessment Methods: History and State of the Art. Boston: Hay McBer.

Spencer, M.L. y M.S. Spencer (1993). Competence at Work: models for superior performance. New York: John Wiley and Sons.

Tolley, G. (1987). Competence Achievement and Qualifications. Industrial And Commercial Training september/october: 6-8.

Totten, M. y J. Orlikoff (2002). Evaluating Trustee performance: Issues, trends, and process. Trustee, january: 1-4.

Tremosa, R y J. Trigo (2003). La empresa textil española en el contexto europeo. Boletín Económico de ICE (2768): 1-10.

Ulrich, D. (1997). Measuring human resources: an overview of practice and a prescription for results. Human Resource Management 36 (3): 303-320.

(2000). Evaluación de resultados. Barcelona: Granica.

Virtanen, T. (2000). Changing competences of public managers: tensions in comitment. The International Journal of Public Sector Management 13 (4): 333-341.

Whiddett, S. y S. Hollyforde (2007). The competencies Handbook, Gran Bretaña: CIPD.

Wood, R. y T. Payne (1999). Competency Based Recruitment and Selection: A practical guide. Gran Bretaña: John Wiley \& Sons. 
Woodruffe, Ch. (1991). Competency by any other name. Personnel Management september: 31-33.

(1993). What is meant by competency. Leadership and Organization Development Journal 14 (1): 29-36.

(2000). Development and Assessment Centres: Identifying and assessing competence. England: Institute of Personnel and Development.

Wright, P. M. y A. S. Snell (1991). Toward an integrative view of strategic human resource management. Human Resource Management Review 1 (3): 203-225.

y C. McMahan (1992). Theoretical Perspectives for Strategic Human Resource Management. Journal of Management 18 (2): 295-320. 